\title{
GLOBAL CHANGES OF THE WATER CYCLE INTENSITY
}

\author{
Michael G. Bosilovich, Siegfried D. Schubert and Greg Walker \\ Global Modeling and Assimilation Office, NASA GSFC, Greenbelt MD
}

\section{INTRODUCTION}

In general, the surface warming that has occurred over the twentieth century leads to increased total precipitable water through increased holding capacity of the atmosphere. Evaporation increases with warmer surface temperatures, and precipitation increases in response to the increased evaporation. In this study, we evaluate the trend of the global water cycle in atmospheric general circulation model (AGCM) simulations that extend over the last fifty years of the twentieth century. In addition to these quantities, we study the cycling rate and the changes of the global cycling rate (and inverse, residence time.

\subsection{Global Water Cycle}

A simple calculation for determining the global water cycling rate can be derived from the atmospheric water vapor budget. If the water vapor budget is vertically integrated and area averaged, the water vapor budget reduces to,

$$
\frac{\partial Q}{\partial t}=E-P
$$

If we, assume that no water enters the atmosphere from surface evaporation (E), the budget can be written as,

$$
\frac{\partial Q}{\partial t}=-P
$$

Here, $Q$ is the total precipitable water content of the atmosphere (in $\mathrm{mm}$ ) and $\mathrm{P}$ is the precipitation (in $\mathrm{mm}$ day-1). If we define a time constant, $\mathrm{I}=$ $P / Q$ and substitute into (2), we obtain

$$
\frac{\partial Q}{\partial t}=-\lambda Q \text {. }
$$

Lambda is the cycling rate of water in the atmosphere and the inverse is the residence time (e-folding time). Chahine et al. (1992) used this method with observed precipitation and total precipitable water (TPW) to estimate a residence time of 10 days for the Earth's atmospheric water vapor.

\footnotetext{
Corresponding Author Address: Michael Bosilovich, Global Modeling and Assimilation Office, NASA GSFC Code 900.3, Greenbelt, MD 20771 email: Michael.Bosilovich@nasa.gov
}

\section{MODELS}

Here, we compare 50-year simulations using real time varying SSTs (Rayner et al. 2003). The models are the Finite Volume GCM (FVGCM, Lin 2003), COLA (Kinter et al., 1997) and NSIPP (Suarez and Takacs, 1995). The NSIPP and COLA data are ensemble mean of 10 simulations and the FVGCM is just one realization. However, the FVGCM includes passive tracers that can diagnose the continental and oceanic sources of water in precipitation (following Bosilovich and Schubert 2002).

\section{GLOBAL WATER CYCLE}

Each of the models has different mean states of the water cycle, so we focus on the anomalies from the 50-year means. Figure 1 shows the globally averaged annual anomalies of surface temperature, precipitation TPW and residence time (TPW/P). In general, the GCMs anomalies are all very well correlated, with increasing trends in precipitation, TPW and residence time. Table 1 shows the values of the trends. The significance of the trends is tested by computing the t-statistic for the trend line, and each trend is found to be significant at the $99 \%$ level (except where noted in the table).

At issue is then how the water cycle intensity is defined. In all the models, both precipitation and evaporation (not shown) are increasing, which may be interpreted as an intensification of the water cycle. On the other hand, the residence time is increasing, so that TPW must be increasing relatively faster than the precipitation. Therefore, the cycling rate of water (inverse of residence time) is decreasing which may be interpreted as a lessening of the intensity of the water cycle. This result is similar to that found by Douville et al. (2002) using a coupled atmosphere ocean GCM, and that of Roads et al (1998) using the Community Climate Model version 3. 


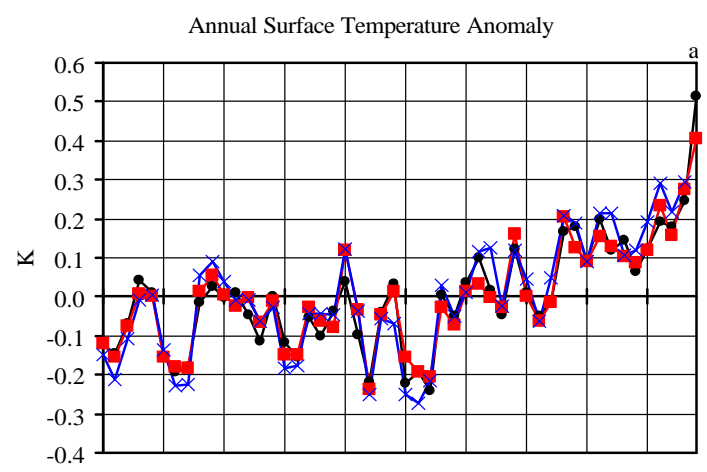

$\begin{array}{llllllllll}1949 & 1954 & 1959 & 1964 & 1969 & 1974 & 1979 & 1984 & 1989 & 1994\end{array}$ Annual Precipitation Anomaly

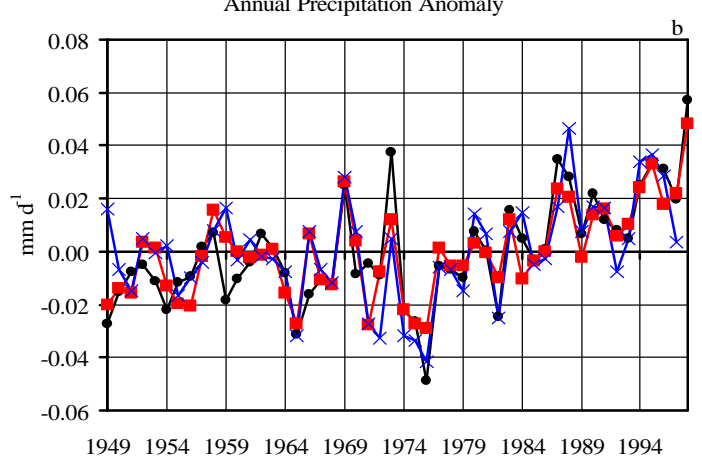
Annual TPW Anomaly

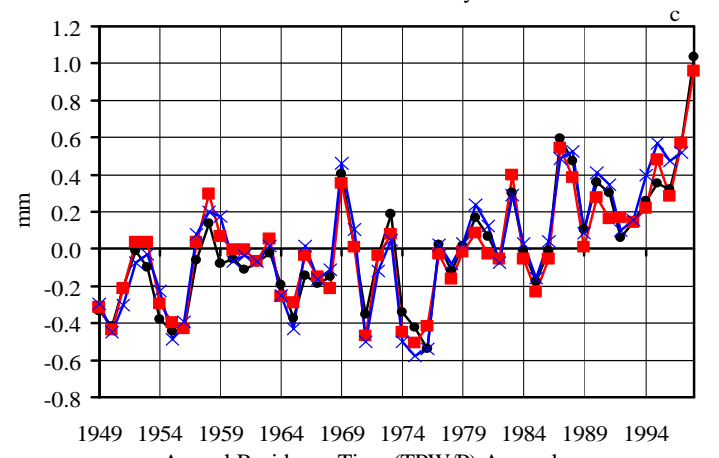
Annual Residence Time (TPW/P) Anomaly

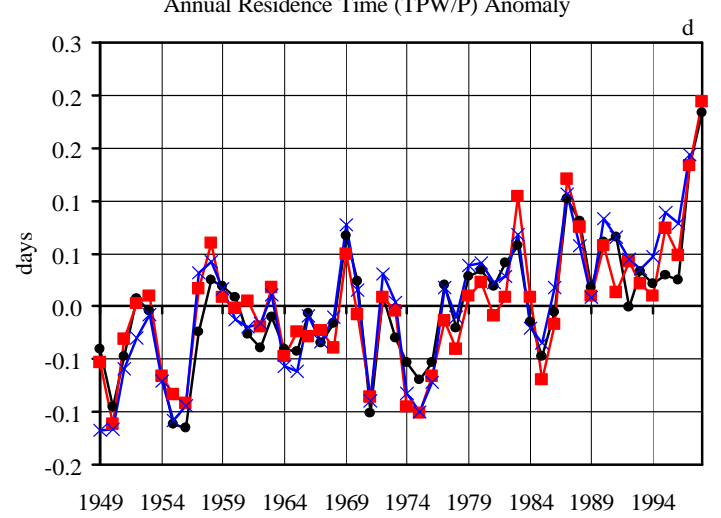

$\rightarrow$ FVGCM $\rightarrow$ NSIPP $*$ COLA

Figure $1 \mathrm{Global}$ and annual average anomalies from long term means for (a) surface temperature, (b) precipitation, (c) total precipitable water, and (d) residence time. Each line represents a different model data set, where black circles - FVGCM, red squares - NSIPP GCM, blue crosses - COLA GCM.
Table 1 Trends of surface temperature, precipitation, total precipitable water (TPW), and residence time (TPW/P) for the periods (a) 1949 - 1998 and (b) $1974-1998$. The units of the variables are the amount of change per 50 years. Using tstatistic, all trends are significant (the trend is significantly different from 0 ) at the $99 \%$ level ( $p$-value $<0.01$ ), except the italicized values, which are significant at $95 \%$. COLA data are evaluated through 1997.

(a) 1949-1998

\begin{tabular}{|l|c|c|c|c|}
\hline $\begin{array}{l}\text { Trends } \\
(\text { per } \\
50 y r)\end{array}$ & $\begin{array}{c}\text { Ts } \\
(\mathrm{K})\end{array}$ & $\begin{array}{c}\mathrm{P} \\
\left(\mathrm{mm} \mathrm{d}^{-1}\right)\end{array}$ & $\begin{array}{c}\text { TPW } \\
(\mathrm{mm})\end{array}$ & $\begin{array}{c}\text { TPW/P } \\
(\text { days })\end{array}$ \\
\hline FVGCM & 0.32 & 0.04 & 0.71 & 0.13 \\
\hline NSIPP & 0.30 & 0.03 & 0.60 & 0.12 \\
\hline COLA & 0.34 & 0.02 & 0.64 & 0.14 \\
\hline
\end{tabular}

(b) 1974-1998

\begin{tabular}{|l|c|c|c|c|}
\hline $\begin{array}{l}\text { Trends } \\
(\text { per } \\
50 \mathrm{yr})\end{array}$ & $\begin{array}{c}\text { Ts } \\
(\mathrm{K})\end{array}$ & $\begin{array}{c}\mathrm{P} \\
\left(\mathrm{mm} \mathrm{d}^{-1}\right)\end{array}$ & $\begin{array}{c}\text { TPW } \\
(\mathrm{mm})\end{array}$ & $\begin{array}{c}\text { TPW/P } \\
(\text { days })\end{array}$ \\
\hline FVGCM & 0.90 & 0.13 & 1.78 & 0.26 \\
\hline NSIPP & 0.85 & 0.10 & 1.83 & 0.34 \\
\hline COLA & 0.93 & 0.11 & 1.85 & 0.31 \\
\hline
\end{tabular}

We also averaged the precipitation over land and oceanic areas separately (Figure 2). Contrary to the global average of precipitation, the land average of precipitation decreases across the 50 -year period. This agrees with the Global Historical Climatology Network (GHCN) land gage observations (Vose et al. 1992), despite the irregularity of the observing network. Oceanic average of precipitation increases in time. The magnitudes of the trends for land and oceanic averages are more than the global average (Table 2). The trends are quite similar for each model and the GHCN observations.

In Figure 3, the precipitation trend is computed at each grid point for the FVGCM, NSIPP and COLA GCMs. There are remarkable regional similarities in the precipitation trends. Notable positive trends over the tropical Pacific Ocean, Indian Ocean and Kurashio Current are apparent in each model. Notable negative trends over the Gulf of Mexico, Caribbean Sea, Amazon, central Africa and north central Pacific Ocean are likewise apparent in each model. The global decreases in continental precipitation are most related to the regional decreases in the tropical land areas (central Africa and Amazon). This agrees with the analysis of tropical precipitation in AGCM simulations by Kumar et al. (2003). The average decrease in precipitation over land is not uniform, as precipitation over the contiguous United States is generally increasing in all the GCMs. Figure 3d shows the trends of GHCN gage precipitation gridded at 5 degrees resolution. The large-scale trends in the central United States and Africa noted in the model simulation agree well with the observations. 
Annual Precipitation (Land) Anomaly

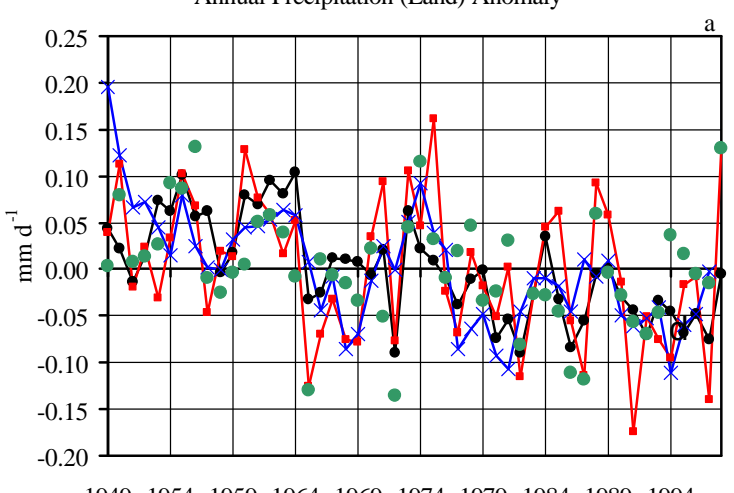

Annual Precipitation (Ocean) Anomaly

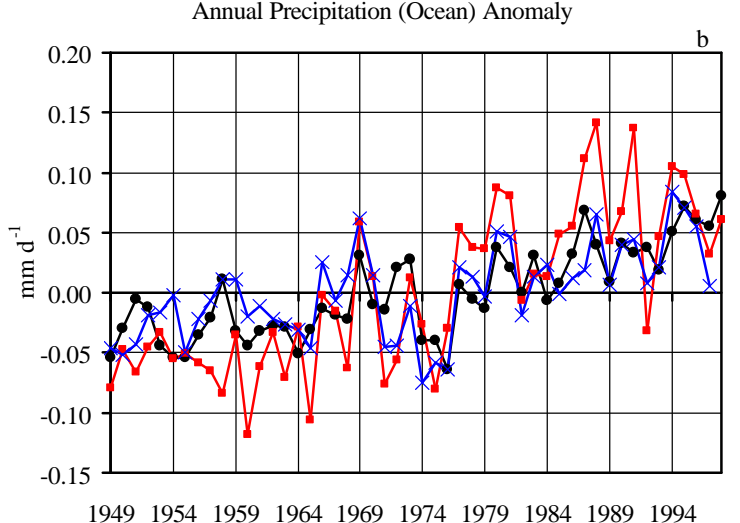

$\rightarrow-$ FVGCM $\rightarrow$ NSIPP $*$ COLA

Figure 2 Annual average anomalies from long-term means for (a) precipitation at global land grid points and (b) precipitation at global ocean gridpoints (including the Antarctic continent). Each line represents a different model data set, where black circles - FVGCM, red squares - NSIPP GCM, blue crosses COLA GCM. The green dots are the global land averaged GHCN gage precipitation data.

Table 2 Trends as in Table 1a except for precipitation averages over land and oceanic regions only. Antarctica is considered in the oceanic average.

\begin{tabular}{|l|c|c|}
\hline $\begin{array}{l}\text { Trend } \\
(\text { per 50 yr })\end{array}$ & $\begin{array}{c}\text { P Land } \\
\left(\mathrm{mm} \mathrm{d}^{-1}\right)\end{array}$ & $\begin{array}{c}\text { P Ocean } \\
\left(\mathrm{mm} \mathrm{d}^{-1}\right)\end{array}$ \\
\hline FVGCM & -0.12 & 0.10 \\
\hline NSIPP & -0.08 & 0.17 \\
\hline COLA & -0.14 & 0.08 \\
\hline GHCN & -0.06 & \\
\hline
\end{tabular}
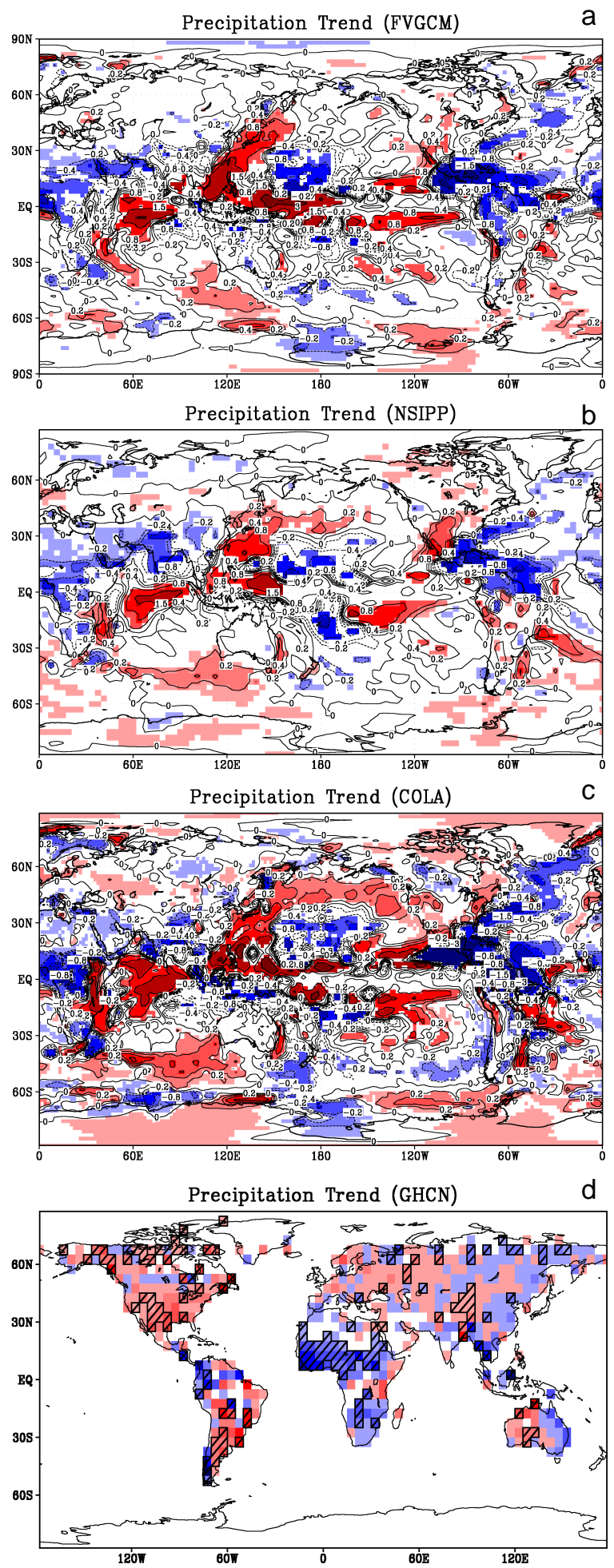

Figure 3 Map of precipitation trends at model gridpoints for (a) FVGCM, (b) NSIPP (c) COLA GCMs and (d) GHCN gage data. The units are mm day- 1 per 50 years. For the GCMs, rends significant at $95 \%$ from t-tests are color shaded, and all values are contoured in black. The 95\% significant trends in the GHCN observations are denoted by crosshatched boxes. 


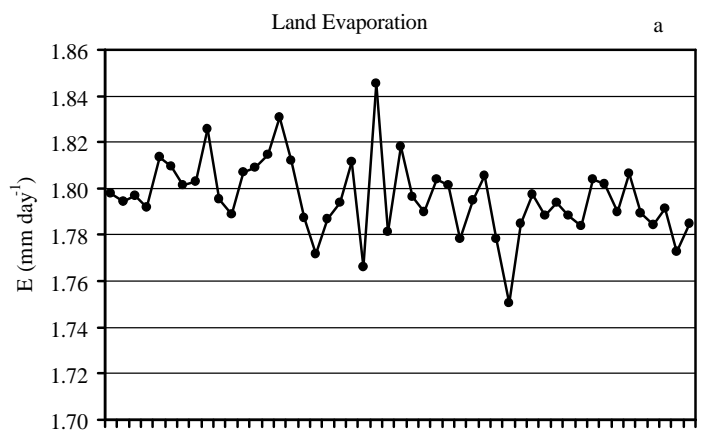

$\begin{array}{llllllllll}1949 & 1954 & 1959 & 1964 & 1969 & 1974 & 1979 & 1984 & 1989 & 1994\end{array}$ Land Precipitation from Land Evaporation

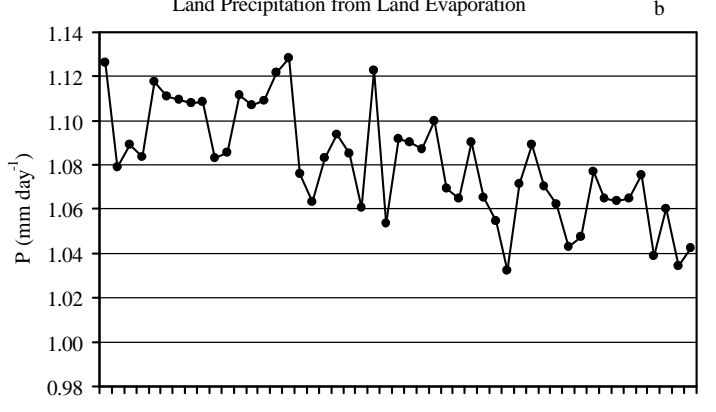

$\begin{array}{llllllllll}1949 & 1954 & 1959 & 1964 & 1969 & 1974 & 1979 & 1984 & 1989 & 1994\end{array}$ Land Precipitation from Ocean Evaporation

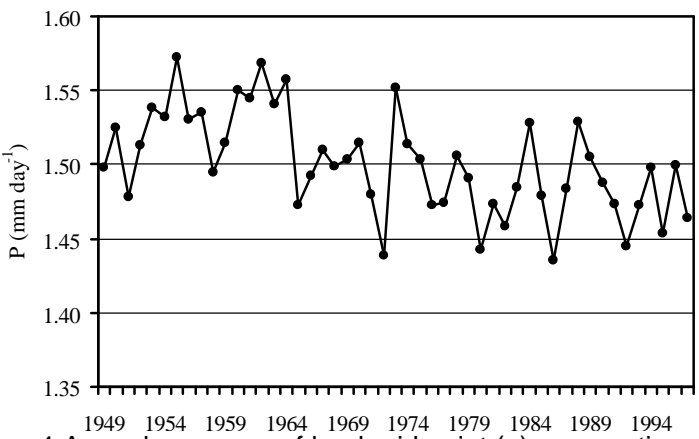

Figure 4 Annual averages of land grid point (a) evaporation, (b) precipitation that occurs from land evaporation and (c) precipitation that occurs from oceanic evaporation (not including the Antarctica continent in the spatial average).

In the FVGCM, water vapr tracers (WVTs) were implemented to tag the surface evaporation from the continental and oceanic sources (following the use of WVTs as regional sources, as in Bosilovich and Schubert, 2002 and Bosilovich et al. 2003). In these experiments, the WVTs allow the diagnosis of how much continental evaporation falls as precipitation over land or ocean. Figure $4 a$ shows the time series of globally averaged FVGCM continental evaporation. The land evaporation is generally decreasing (see also Table 3). The precipitation over land from both land sources and oceanic sources are decreasing (Table 3 and Figure $4 \mathrm{~b}$ and $\mathrm{c}$ ). Oceanic sources of precipitation over land appear to stabilize for the last 25 years of the simulation (when surface temperatures are generally increasing). Continental sources of land precipitation decrease over the whole 50-year period. The decrease of land evaporation does not extend to the most recent 25 years.

Table 3 Trends as in Table 1, except for the land average time series of evaporation, precipitation that originated as land evaporation and precipitation that originated as oceanic evaporation. The trends are computed for the 50 year period and the last 25 year period. Using t-statistic, all trend are significant (the trend is significantly different from 0 ) at the $99 \%$ level ( $p$-value $<0.01$ ), except the italicized values, which are significant at $95 \%$. Grey shaded cells are not significant at $95 \%$. The units are trend of vapor flux in $\mathrm{mm}$ day-1 per 50 years.

\begin{tabular}{|c|c|c|}
\hline $\begin{array}{l}\text { Trend } \\
\text { (per } \\
\text { year) }\end{array}$ & $\begin{array}{c}\text { FVGCM Land } \\
\text { Average } \\
50 \text { yrs. } \\
\left(\mathrm{mm} \mathrm{day}^{-1}\right)\end{array}$ & $\begin{array}{c}\text { FVGCM Land } \\
\text { Average } \\
25 \text { yrs. } \\
\left(\mathrm{mm} \mathrm{day}^{-1}\right)\end{array}$ \\
\hline Evaporation & -0.016 & 0.006 \\
\hline $\mathrm{P}($ Land $\mathrm{E})$ & -0.060 & -0.062 \\
\hline $\mathrm{P}($ Ocean E) & -0.062 & -0.020 \\
\hline
\end{tabular}

Figure $5 \mathrm{a}$ and $\mathrm{b}$ shows the trend of precipitation from land sources and the trend of precipitation from oceanic sources. While these trends generally follow that of the total precipitation (Figure 3a), several distinct differences are apparent. First, while trends in precipitation from oceanic sources are positive over the central United States, the values are relatively small and not statistically significant. However, the trend of precipitation from continental sources over the central United States is more significant. This differs from the tropical land regions (specifically the Amazon and central Africa) where both trends in land and oceanic sources are large and comparable.

Table 4 shows the trend of area averaged precipitation, evaporation and surface temperature for the Mississippi and Amazon River basins. The increasing trend of precipitation is related to the increasing trend of precipitation from continental sources. This result is in agreement with the analysis of Mississippi River basin sources of water by Brubaker et al. (2001) using observational and reanalysis data. The evaporation within the Mississippi River basin is likewise increasing, but surface temperature changes do not experience a significant trend. In the Amazon, the precipitation trend is the result of changes in both continental and oceanic sources of water. The Amazon evaporation experiences little change over the whole period, but a more decreasing trend in the last half of the 50-year period, while surface temperatures continually increase. While it is not the purpose of this paper to discuss the changes of regional water cycles indepth, this analysis demonstrates the range of 


\section{5}

regional variability of the water cycle intensity changes. Furthermore, the changes in continental precipitation and local cycling of water are likely seasonally dependent (as discussed by Wetherald and Manabe, 1999). In order to specifically quantify precipitation recycling in these basins, new simulations that isolate the sources of water from those regions will be performed.
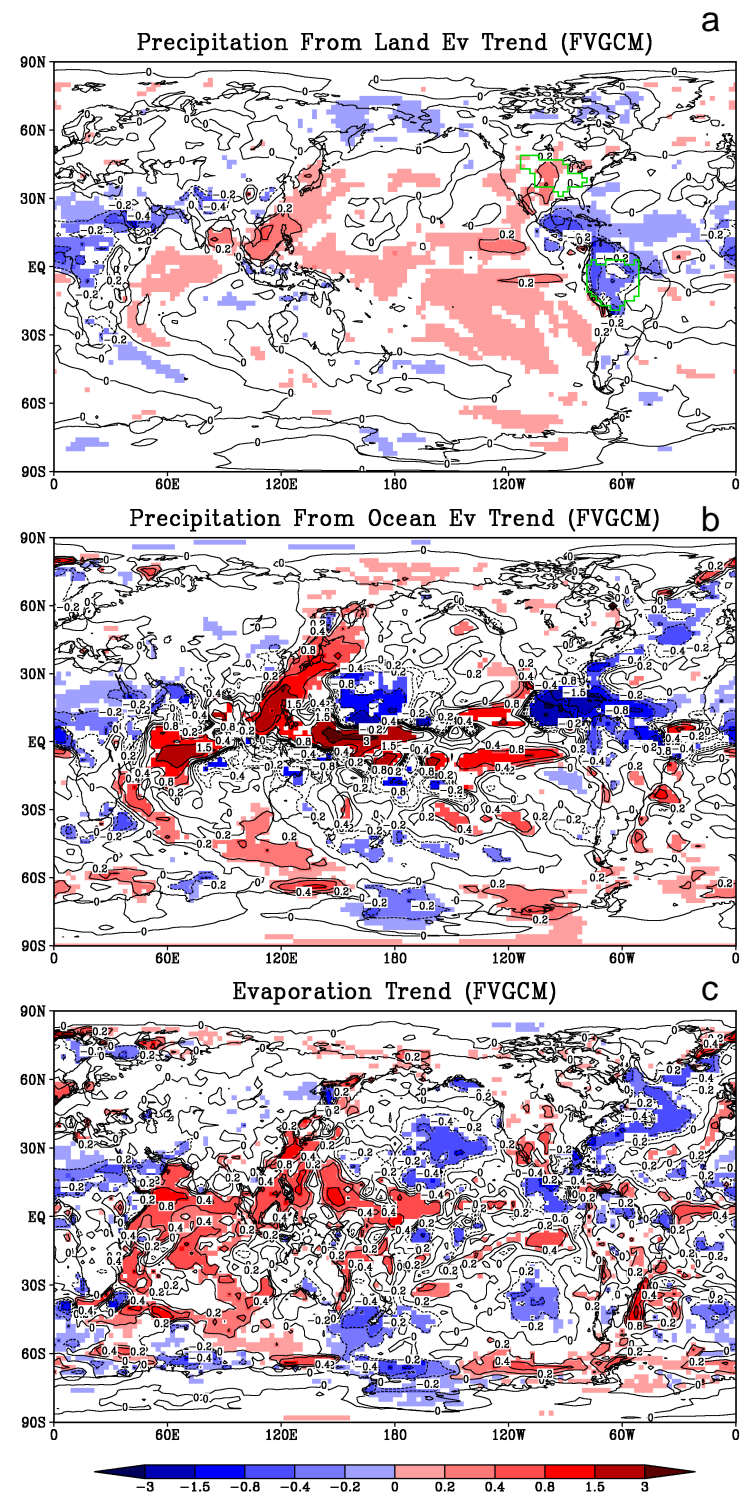

Figure 5 Map of trends at model gridpoints for the FVGCM (a) precipitation that has a continental evaporative source, (b) precipitation that has an oceanic evaporative source and (c) surface evaporation. The regions in (a) outlined in green denote the areas for Mississippi River and Amazon River basin averages.

\section{SUMMARY}

The evolution of the hydrologic cycle was tested using several 50-year model simulations forced with observed time varying SSTs. The SST warming in the 50-year simulations drives increased evaporation and precipitation. Taken in isolation, this implies the water cycle is intensifying. On the other hand, the total precipitable water increases with warming and therefore the residence time of water increases, despite the increase of precipitation. The fact that water is spending more time in the atmosphere implies that the global cycling rate is decreasing. The 50-year simulations from three models with different physical parameterizations all provide the same conclusions. In most cases, the increasing trends of precipitation (and evaporation), TPW and residence time were statistically significant in all the GCMs evaluated.

Table 4 Regional trends in the Mississippi River Basin (MRB) and Amazon River Basin of total precipitation (P), precipitation from land evaporation (PI), precipitation from oceanic evaporation (Po), Evaporation within the region (E) and surface temperature (Ts). The units are $\mathrm{mm}$ day- 1 and $\mathrm{K}$, per 50 years. Values are significant at $95 \%$, except italicized $(90 \%)$ and gray shaded (not significant at $90 \%$ ).

\begin{tabular}{|l|c|c|}
\hline MRB & Trend (1949-1998) & Trend (1974-1998) \\
\hline$P$ & 0.16 & 0.30 \\
\hline$P_{1}$ & 0.16 & 0.23 \\
\hline$P_{0}$ & 0.00 & 0.07 \\
\hline$E$ & 0.10 & 0.18 \\
\hline$T_{s}$ & -0.10 & 0.77 \\
\hline Amazon & \multicolumn{2}{|l|}{} \\
\hline$P$ & -0.40 & -0.84 \\
\hline$P_{1}$ & -0.26 & -0.43 \\
\hline$P_{0}$ & -0.14 & -0.41 \\
\hline$E$ & 0.01 & -0.15 \\
\hline$T_{s}$ & 0.47 & 1.25 \\
\hline
\end{tabular}

In the global average sense, the precipitation trend over land is decreasing, while the trend over oceans increases. The magnitude of these trends exceeds that of the total global average (land and ocean combined) so that the increasing global trend is not necessarily representative of the globe. Furthermore, the contrasting land and ocean trends are not universally applicable to all regions. For example, the precipitation over the North American continent is increasing, while the precipitation trend over the Gulf of Mexico is decreasing.

Tracer diagnostics that delineate ocean and continental sources of water show that the continental sources of water for precipitation over land decrease continually through out the last 50 years of the 20th century. The ocean sources of precipitation over land have virtually no trend over land in the last 25 years of the 20th century. There are distinct and significant changes in different 


\section{5}

directions depending on the region. Continental cycling of water appears to be decreasing in time, except for the central United States, where continental cycling may be increasing. Further study is needed with a regional focus and with more detailed diagnostics that can quantify the local recycling rates. This study specifically evaluates model trends and changes driven by realistic ocean surface temperatures. Global observations of the water cycle on this time and space are not readily available. However, these results suggest some parameters to be evaluated in the future study of 20th century climate change and in climate change prediction scenarios.

\section{REFERENCES}

Bosilovich, M. G. and S. D. Schubert, 2002: Water vapor tracers as diagnostics of the regional hydrologic cycle, J. Hydromet., 3, 149-165.

Bosilovich, M. G., Y. C. Sud, S. D. Schubert and G. K. Walker, 2003: Numerical simulation of the North American monsoon water sources. J. Geophys. Res., 108(D16), 8614, doi:10.1029/2002JD003095.

Brubaker, K. L., P. A. Dirmeyer, A. Sudradjat, B. S. Levy and F. Bernal, 2001: A 36-year climatological description of the evaporative sources of warm-season precipitation in the Mississippi River Basin. J. Hydromet., 2, 537-557.

Chahine, M. T., 1992: The hydrological cycle and its influence on climate, Nature, 356, 373-380.

Douville, H., F. Chauvin, S. Planton, J.-F. Royer, D. SalasMelia and S. Tyteca, 2002: Sensitivity of the hydrological cycle to increasing amounts of greenhouse gasses and aerolsols. Clim. Dyn., 20, 45-68.

Kinter, J. L., D. DeWitt, P. A. Dirmeyer, M. J. Fennessy, B. P. Kirtman, L. Marx, E. K. Schneider, J. Shukla, and D. M. Straus, 1997: The COLA atmosphere-biosphere general circulation model. Volume 1: Formulation. COLA Technical Report 51 [Available from the Center for OceanLand-Atmosphere Studies, 4041 Powder Mill Road, Suite 302, Calverton, MD 20705 USA], 46 pp.

Kumar, A., F. Yang, L. Goddard and S. D. Schubert, 2003: Differing trends in the tropical surface temperatures and precipitation over land and oceans. Accepted for publication in the Journal of Climate.

Lin, S.-J., 2003: A "vertically Lagrangian" finite-volume dynamical core for global models. Submitted to Mon. Wea. Rev.

Rayner, N. A., D. E. Parker, E. B. Horton, C. K. Folland, L. V. Alexander, D. P. Rowell, E. C. Kent, and A. Kaplan, 2003: Global analyses of sea surface temperature, sea ice, and night marine air temperature since the late nineteenth century, J. Geophys. Res., 108(D14), 4407, doi:10.1029/2002JD002670.

Roads, J. O., S. C. Chen, S. Marshall and R. Oglesby, 1998: Atmospheric moisture cycling rates. GEWEX News, 8, 710.

Suarez, M. J. and L. L. Takacs, 1995: Documentation of the Aries-GEOS dynamical core: Version 2, NASA Tech Memo 104606, vol. 5, pp. 45.

Vose, R., R. Schmoyer, P. Steurer, T. Peterson, R. Heim, T. Karl and J. Eischeid, 1992: The Global Historical Climatology Network: Long-term Monthly Temperature, Precipitation Sea Level Pressure and Station Pressure data. ORNL/CDIAC-53,NDP-041. Carbon Dioxide Information Analysis Center, Oak Ridge National Laboratory, Oak Ridge Tennessee. 